\title{
Indacaterol/glycopyrronium in symptomatic
} patients with COPD (GOLD B and GOLD D) versus salmeterol/fluticasone: ILLUMINATE/ LANTERN pooled analysis

\author{
This article was published in the following Dove Press journal: \\ International Journal of COPD \\ 14 December 2016 \\ Number of times this article has been viewed
}

\author{
Claus Vogelmeier \\ Nanshan Zhong ${ }^{2}$ \\ Michael J Humphries ${ }^{3}$ \\ Karen Mezzi ${ }^{4}$ \\ Robert Fogel ${ }^{5}$ \\ Giovanni Bader 4 \\ Francesco Patalano 4 \\ Donald Banerji ${ }^{5}$ \\ 'Department of Medicine, Pulmonary \\ and Critical Care Medicine, University \\ Medical Center Giessen and \\ Marburg, Philipps-University Marburg, \\ Member of the German Center \\ for Lung Research (DZL), Marburg, \\ Germany; ${ }^{2}$ State Key Laboratory, \\ Guangzhou Institute of Respiratory \\ Diseases, First Affiliated Hospital, \\ Guangzhou Medical University, \\ Guangzhou, ${ }^{3}$ Beijing Novartis \\ Pharma Co. Ltd., Shanghai, People's \\ Republic of China; ${ }^{4}$ Novartis Pharma \\ AG, Basel, Switzerland; ${ }^{5}$ Novartis \\ Pharmaceuticals Corporation, East \\ Hanover, NJ, USA
}

Background: Indacaterol/glycopyrronium (IND/GLY) is approved for maintenance treatment of adult patients with COPD. This post hoc analysis explored the efficacy and safety of IND/GLY versus salmeterol/fluticasone (SFC) in symptomatic (Global Initiative for Chronic Obstructive Lung Disease [GOLD] B and GOLD D) patients with moderate-to-severe COPD.

Patients and methods: Data from LANTERN and ILLUMINATE studies were pooled and analyzed. In both studies, symptomatic COPD patients were randomized to once-daily IND/ GLY $110 \mu \mathrm{g} / 50 \mu \mathrm{g}$ or twice-daily SFC $50 \mu \mathrm{g} / 500 \mu \mathrm{g}$. End points were pre-dose trough forced expiratory volume in one second $\left(\mathrm{FEV}_{1}\right)$, standardized area under the curve for $\mathrm{FEV}_{1}$ from 0 to 12 hours $\left(\mathrm{FEV}_{1} \mathrm{AUC}_{0-12 \text { hours }}\right)$, peak $\mathrm{FEV}_{1}$, peak forced vital capacity (FVC), pre-dose trough FVC, Transition Dyspnea Index (TDI) total score, St George's Respiratory Questionnaire total score, rescue medication use and safety.

Results: A total of 1,263 patients were classified as either GOLD B ( $\mathrm{n}=809)$ or GOLD D ( $\mathrm{n}=454)$. At week 26, IND/GLY demonstrated statistically significant improvement in all lung function parameters versus SFC in patients in both the GOLD B and GOLD D subgroups. TDI total score and rescue medication use were significantly improved with IND/GLY versus SFC in the overall population and in the GOLD B (TDI total score only) and GOLD D (rescue medication only) subgroups. IND/GLY also reduced the rate of exacerbations in the pooled population. Overall safety profile was comparable with a higher incidence of pneumonia in the SFC-treated group.

Conclusion: In this pooled analysis, IND/GLY demonstrated superior efficacy compared with SFC in patients in the GOLD B and GOLD D subgroups and supported its use in symptomatic COPD patients.

Keywords: COPD, exacerbation, LABA/LAMA, LABA/ICS, lung function

\section{Introduction}

COPD is usually a progressive lung disease. The Global Initiative for Chronic Obstructive Lung Disease (GOLD) strategy classifies patients with COPD into GOLD groups A to D, based on individual risk, in terms of airflow limitation, symptoms, and history of exacerbations. Patients with mild (GOLD I, forced expiratory volume in one second $\left[\mathrm{FEV}_{1}\right] \geq 80 \%$ predicted) and moderate (GOLD II, $50 \leq \mathrm{FEV}_{1}>80 \%$ predicted) severities in lung function and high symptomatic burden (modified Medical Research Council [mMRC] grade $\geq 2$ or COPD assessment test score $>10$ ) with a lower risk of exacerbation are categorized into GOLD B, whereas those with high symptomatic
Correspondence: Claus Vogelmeier Department of Medicine, Pulmonary and Critical Care Medicine, University Medical Center Giessen and Marburg, Philipps-University Marburg, Member of the German Center for Lung Research (DZL), Marburg 35043, Germany Email claus.vogelmeier@med.unimarburg.de (c) (7) (5) 2016 Vogelmeier et al. This work is published and licensed by Dove Medical Press Limited. The full terms of this license are available at https://www.dovepress.com/terms.php cc. hereby accept the Terms. Non-commercial uses of the work are permitted without any further permission from Dove Medical Press Limited, provided the work is properly attributed. For permission for commercial use of this work, please see paragraphs 4.2 and 5 of our Terms (https://www.dovepress.com/terms.php). 
burden and severe (GOLD III, $30 \leq \mathrm{FEV}_{1}>50 \%$ predicted) or very severe (GOLD IV, $\mathrm{FEV}_{1}<30 \%$ predicted) impairment in lung function and/or a history of exacerbations are categorized into GOLD D. ${ }^{1}$

Recommendations for initial treatment for patients with different severities are also based on this classification. The strategy recommends a long-acting $\beta_{2}$-agonist (LABA) or long-acting muscarinic antagonist (LAMA) monotherapy for patients in the GOLD B subgroup and a LABA/inhaled corticosteroid (ICS) combination and/or LAMA for patients in the GOLD D subgroup, as the first choice of treatment, whereas LABA/LAMA combination is recommended as an alternative treatment for patients belonging to GOLD B and GOLD D. The strategy recommends that ICS should be reserved for patients with severe airflow limitation and high risk of exacerbations (GOLD C and GOLD D), as they are most likely to benefit. However, in current clinical practice, many patients with moderate COPD (GOLD B) are inappropriately receiving LABA/ICS treatment.,

Indacaterol/glycopyrronium (IND/GLY) is an inhaled, once-daily (OD) fixed-dose dual bronchodilator, combining the LABA IND $110 \mu \mathrm{g}$ and the LAMA GLY $50 \mu \mathrm{g}$, delivered by the Breezhaler ${ }^{\circledR}$ device, and is approved for the maintenance treatment to relieve symptoms in adult patients with COPD. The efficacy and safety of IND/GLY have been reported in a number of clinical trials that showed additional therapeutic benefits over placebo, its monocomponents and tiotropium. ${ }^{4,5}$ The ILLUMINATE study previously demonstrated the superiority of IND/GLY compared with salmeterol/fluticasone (SFC), a LABA/ICS combination, in patients with moderate-to-severe COPD without a history of moderate or severe exacerbation in the previous year. ${ }^{6}$ Furthermore, the LANTERN study confirmed superior bronchodilation with IND/GLY versus SFC, along with reduction in the rates of moderate or severe exacerbation in moderateto-severe COPD patients with a history of $\leq 1$ exacerbation in the previous year. ${ }^{7}$ Despite increasing evidence that combining bronchodilators of different pharmacological classes provides additional benefit over the use of a single agent and LABA/ICS combination, within the GOLD strategy, dual bronchodilation with a LABA/LAMA is classed as an alternative treatment choice for patients whose symptoms are inadequately controlled with monotherapy.

In this post hoc analysis, we further explore the efficacy and safety of the LABA/LAMA combination, IND/GLY, versus the LABA/ICS combination, SFC, from a pooled analysis of two double-blind randomized clinical trials, ILLUMINATE and LANTERN, in all randomized patients and also in patients belonging to the GOLD B and GOLD D categories. Although the inclusion criteria for ILLUMINATE and LANTERN were determined before the GOLD assessment strategy (GOLD 2011), patients were grouped into GOLD B or GOLD D, by virtue of $\mathrm{FEV}_{1}$, symptoms and history of exacerbations before study entry. Data from the two randomized clinical trials were pooled, and patients were classified into GOLD B or GOLD D subgroup based on lung function, symptoms and history of exacerbations at baseline.

\section{Patients and methods \\ Study design}

This was a pooled analysis of two phase III clinical studies, ILLUMINATE and LANTERN, which were 26-week, multicenter, randomized, double-blind, parallel-group, double-dummy studies on symptomatic COPD patients comparing IND/GLY with SFC. These studies are registered

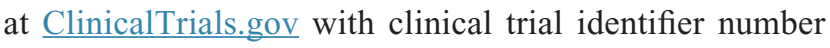
NCT01315249 (ILLUMINATE) and NCT01709903 (LANTERN). The study details and primary outcomes have been published previously. ${ }^{6,7}$ Following the screening and run-in periods, eligible patients were randomized (1:1) to IND/GLY $110 \mu \mathrm{g} / 50 \mu \mathrm{g}$ OD (via the Breezhaler ${ }^{\circledR}$ device) or SFC $50 \mu \mathrm{g} / 500 \mu \mathrm{g}$ twice daily (via the Accuhaler ${ }^{\circledR}$ device) during the 26-week, double-blind treatment period followed by a 30-day safety follow-up. Both studies were approved by the international and local ethics review boards and were conducted in accordance with the Declaration of Helsinki and Good Clinical Practice guidelines. All patients provided written informed consent prior to study entry. As this was a pooled post hoc analysis with the data being taken from original studies (where ethical approval was granted), ethics committee approval was not sought.

\section{Patients}

Both studies enrolled male and female patients aged $\geq 40$ years, with a clinical diagnosis of moderateto-severe COPD (Stage II or III) according to the GOLD strategy (ILLUMINATE; GOLD 2009 and LANTERN; GOLD 2010). Patients were included if they had postbronchodilator $\mathrm{FEV}_{1}$ of $\geq 40 \%$ and $<80 \%$ (ILLUMINATE; GOLD 2009) and $\geq 30 \%$ and $<80 \%$ (LANTERN; GOLD 2010) of the predicted normal value and $\mathrm{FEV}_{1} /$ forced vital capacity $(\mathrm{FVC}$ ) ratio of $<0.7$. All patients were symptomatic according to daily electronic diary (e-diary) data, with a total score of 1 or more for at least 4 days out of the 7 days run-in period in the ILLUMINATE study and as defined by the mMRC dyspnea scale grade of $\geq 2$ in the LANTERN 
study. Patients were excluded from these studies if they had experienced any moderate-to-severe exacerbation (ILLUMINATE) or $\geq 2$ COPD exacerbations (LANTERN) requiring treatment with antibiotics and/or oral corticosteroids and/ or hospitalization in the year prior to screening or during the run-in period. In both ILLUMINATE and LANTERN studies, patients were classified into GOLD B or GOLD D subgroups by virtue of $\mathrm{FEV}_{1}$, e-diary-based symptoms (in the ILLUMINATE) or mMRC grade $\geq 2$ (in the LANTERN) and history of exacerbations before study entry.

\section{Assessments}

Lung function was evaluated using centralized spirometry at all clinical visits. In this article, we present the results at week 26. Lung function improvements with IND/GLY versus SFC in the pooled patient population was measured via pre-dose trough $\mathrm{FEV}_{1}$ (average values of $\mathrm{FEV}_{1}$ at -45and -15-minute pre-dose), standardized area under the curve for $\mathrm{FEV}_{1}$ from 0 to 12 hours $\left(\mathrm{FEV}_{1} \mathrm{AUC}_{0-12 \text { hours }}\right)$, peak $\mathrm{FEV} \mathrm{V}_{1}$ ( 5 minutes to 4 hours), peak FVC ( 5 minutes to 4 hours), and pre-dose trough FVC (average values of FVC at -45 - and -15 -minute pre-dose).

Dyspnea and health status were assessed by using the Transition Dyspnea Index (TDI) total score and St George's Respiratory Questionnaire (SGRQ) total score, respectively, at week 26. Rescue medication use and COPD exacerbations during the 26-week treatment period were analyzed in the overall pooled population and also in the GOLD B and GOLD D subgroups.

Safety was assessed by monitoring adverse events (AEs) and serious AEs (SAEs) during the studies. Mortality and cardiovascular (CV) SAEs were adjudicated by an independent adjudication committee.

\section{Statistical analysis}

For this post hoc analysis, data were pooled from the two randomized multicenter, double-blind, parallel group, double dummy studies, with same duration, design, and comparator (SFC). Baseline and 26-week data from both studies were appended and the intention-to-treat population was analyzed. The principal objective was to compare the main clinical efficacy parameters between the two treatment arms in the overall patient population and across two classes of COPD groups based on the GOLD classification (GOLD B and GOLD D). Main demographic parameters were analyzed by means of descriptive statistics. For the efficacy parameters, an analysis of covariance model was used with treatment, smoking history, inhaled steroids at baseline, symptoms score,
$\mathrm{FEV}_{1}$ reversibility, history of exacerbation and region as covariates. No adjustment for multiplicity was performed.

The rate of moderate or severe COPD exacerbation was analyzed by a negative binomial model, and incidence rate per year was reported. Time to first exacerbation was analyzed by the log-rank test, and $P$-values were reported. Hazard ratio for time-to-first moderate or severe exacerbation was calculated by Cox's proportional hazards model.

Statistical analysis was performed using Statistical Analysis Software (SAS) version 9.3 (SAS Institute, Cary, NC, USA).

\section{Results}

\section{Patients}

A total of 1,263 patients included in this pooled analysis (IND/GLY, $n=630 ;$ SFC, $n=633$ ) were classified into the GOLD B $(n=809)$ or GOLD D $(n=454)$ subgroups. Demographics and baseline characteristics of patients belonging to the GOLD B and GOLD D subgroups were similar across the IND/GLY and SFC treatment groups (Table 1). In both the subgroups, the majority of patients were male and current smokers. Notably, at baseline, $\sim 50 \%$ of patients within the GOLD B subgroup were using ICS, despite $\sim 90 \%$ experiencing no exacerbation in the previous year.

\section{Efficacy}

\section{Lung function}

Pre-dose trough $\mathrm{FEV}_{1}$ improved significantly with IND/GLY versus SFC in the overall population (treatment difference, $0.10 \mathrm{~L} ; P<0.0001$ ) as well as in the GOLD B (treatment difference, $0.10 \mathrm{~L} ; P<0.0001)$ and GOLD D (treatment difference, $0.08 \mathrm{~L} ; P<0.0001$ ) subgroups of patients (Figure 1).

Significant improvements in lung function in terms of $\mathrm{FEV}_{1} \mathrm{AUC}_{0-12 \text { hours }}$ were observed with IND/GLY versus $\mathrm{SFC}$ in the overall population (treatment difference, $0.13 \mathrm{~L}$; $P<0.0001$ ) and also in the GOLD B (treatment difference, $0.14 \mathrm{~L} ; P<0.0001$ ) and GOLD D (treatment difference, $0.11 \mathrm{~L}$; $P<0.005$ ) subgroups (Figure 2 ). All patients from the ILLUMINATE study and a subset of patients from the LANTERN study were included in the $\mathrm{FEV}_{1} \mathrm{AUC}_{0-12 \text { hours }}$ analysis.

Improvements in lung function assessed via other parameters such as peak $\mathrm{FEV}_{1}$, peak FVC, and pre-dose trough FVC with IND/GLY versus SFC were significant at week 26 (Table 2).

\section{Dyspnea, rescue medication use and health status}

Improvement in dyspnea (as measured by TDI total score) and changes from baseline in rescue medication use were statistically significant with IND/GLY versus SFC in the 
Table I Patient demographics and baseline characteristics

\begin{tabular}{|c|c|c|c|c|c|c|}
\hline \multirow[t]{2}{*}{ Parameters } & \multicolumn{2}{|l|}{ Overall } & \multicolumn{2}{|l|}{ GOLD B } & \multicolumn{2}{|l|}{ GOLD D } \\
\hline & $\begin{array}{l}\text { IND/GLY } \\
(n=630)\end{array}$ & $\begin{array}{l}\text { SFC } \\
(n=633)\end{array}$ & $\begin{array}{l}\text { IND/GLY } \\
(n=401)\end{array}$ & $\begin{array}{l}\text { SFC } \\
(n=408)\end{array}$ & $\begin{array}{l}\text { IND/GLY } \\
(n=229)\end{array}$ & $\begin{array}{l}\text { SFC } \\
(n=225)\end{array}$ \\
\hline Age, mean (SD), years & $64.1(5.7)$ & $64.5(6.1)$ & $63.8(8.1)$ & $64.8(8.1)$ & $64.7(7.8)$ & $64.0(7.4)$ \\
\hline Male, $n(\%)$ & $522(82.9)$ & $520(82.1)$ & $317(79.0)$ & $317(77.7)$ & $205(89.5)$ & $203(90.2)$ \\
\hline \multicolumn{7}{|l|}{ Race, n (\%) } \\
\hline Caucasian & $286(45.4)$ & $293(46.3)$ & $217(54.1)$ & $220(53.9)$ & $69(30.1)$ & $73(32.4)$ \\
\hline Asian & $34 I(54.1)$ & $338(53.4)$ & $183(45.6)$ & $187(45.8)$ & $158(69.0)$ & I5I (67.I) \\
\hline Native American & $2(0.3)$ & $I(0.2)$ & $\mathrm{I}(0.3)$ & I $(0.3)$ & $0(0)$ & I $(0.4)$ \\
\hline Duration of COPD, mean (SD), years & $5.7(5.1)$ & $6.1(5.4)$ & $5.4(4.7)$ & $6.1(5.6)$ & $6.2(5.6)$ & $6.3(5.0)$ \\
\hline ICS use at screening, $n$ (\%) & $291(46.2)$ & $298(47.1)$ & $174(48.2)$ & $187(5 \mid .8)$ & $117(5 \mid .3)$ & II I (48.7) \\
\hline \multicolumn{7}{|l|}{ Smoking status, n (\%) } \\
\hline Ex-smoker & $4 I I(65.2)$ & $410(64.8)$ & $248(49.9)$ & $249(50.1)$ & $163(50.3)$ & $161(49.7)$ \\
\hline Smoker & $219(34.8)$ & $223(35.2)$ & $153(49.0)$ & $159(5 \mathrm{I} .0)$ & $66(50.8)$ & $64(49.2)$ \\
\hline \multicolumn{7}{|l|}{ COPD exacerbations in the previous year, $\mathrm{n}(\%)$} \\
\hline 0 & $569(90.3)$ & $539(85.2)$ & $370(92.3)$ & $361(88.5)$ & $199(86.9)$ & I $78(79.1)$ \\
\hline 1 & $60(9.5)$ & $94(14.8)$ & $30(7.5)$ & $47(11.5)$ & $30(13.1)$ & $47(20.9)$ \\
\hline Post-bronchodilator $\mathrm{FEV}_{1}$, mean (SD), \% predicted & $55.2(12.7)$ & $55.3(12.6)$ & $63.0(8.3)$ & $62.9(8.3)$ & $4 I .5(5.5)$ & $41.4(5.4)$ \\
\hline
\end{tabular}

Abbreviations: $\mathrm{FEV}_{1}$, forced expiratory volume in one second; GOLD, Global Initiative for Chronic Obstructive Lung Disease; ICS, inhaled corticosteroid; IND/GLY, indacaterol/glycopyrronium ( $10 \mu \mathrm{g} / 50 \mu \mathrm{g}$ OD); OD, once daily; SD, standard deviation; SFC, salmeterol/fluticasone $(50 \mu \mathrm{g} / 500 \mu \mathrm{g}$ twice daily).

overall population and in the GOLD B (TDI only) and GOLD D (rescue medication use only) subgroups (Table 2). Changes in health status (SGRQ total score) were comparable between IND/GLY and SFC in the overall population and in the GOLD B and GOLD D subgroups (Table 2).

\section{Exacerbations}

Exacerbation rates were generally low in both treatment arms. In the overall pooled population, the annualized rate of moderate or severe exacerbations was significantly lower with IND/GLY versus SFC (incidence rate ratio [IRR], 0.67;
$P=0.02$; Figure 3). In both the subgroups (GOLD B and GOLD D), the annualized rate of moderate or severe exacerbations was also lower with IND/GLY versus SFC (IRR, $0.72, P=0.16$ and $0.62, P=0.05$, respectively; Figure 3 ). In terms of risk, IND/GLY delayed the time-to-first moderate or severe exacerbation versus SFC in the overall population and also in the GOLD B and GOLD D subgroups (Figure 4).

\section{Safety}

The percentage of patients with AEs was similar between treatments in both the GOLD B and GOLD D subgroups

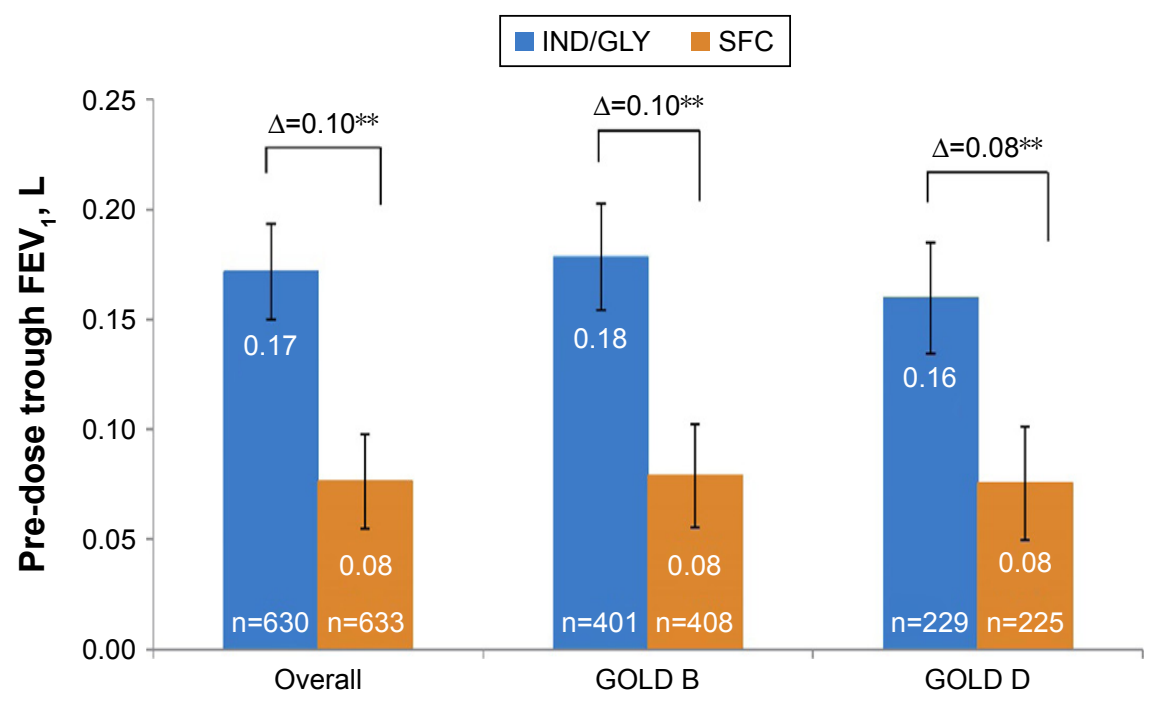

Figure I Change from baseline in pre-dose trough FEV, at week 26

Notes: Data are least squares mean (standard error); $* * P<0.00$ I.

Abbreviations: FEV , forced expiratory volume in one second; GOLD, Global Initiative for Chronic Obstructive Lung Disease; IND/GLY, indacaterol/glycopyrronium $110 \mu \mathrm{g} / 50 \mu \mathrm{g}$ once daily; $\mathrm{n}$, number of patients; SFC, salmeterol/fluticasone $50 \mu \mathrm{g} / 500 \mu \mathrm{g}$ twice daily. 


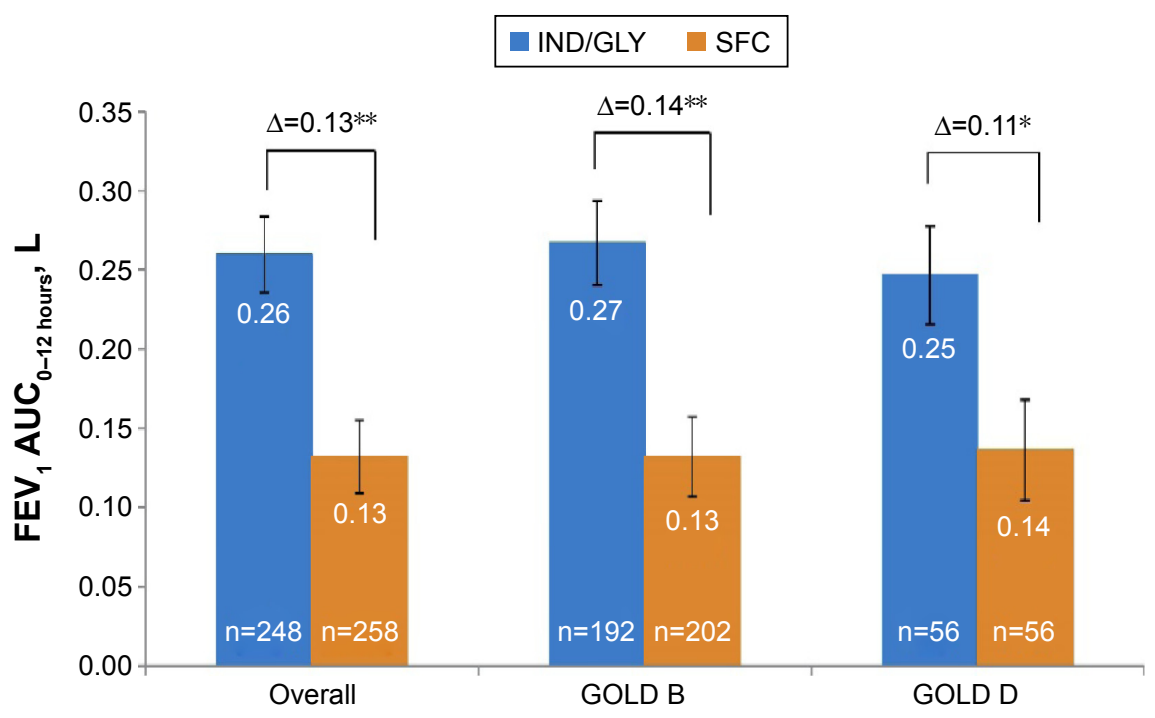

Figure 2 Change from baseline in $\mathrm{FEV}_{1} \mathrm{AUC}_{0-12 \text { hours }}$ at week 26.

Notes: Data are least squares mean (standard error); $* * P<0.001 ; * P<0.005$

Abbreviations: FEV $A \mathrm{AC}_{0-12 \text { hours }}$, area under the curve for forced expiratory volume in one second from 0 to 12 hours; GOLD, Global Initiative for Chronic Obstructive Lung Disease; IND/GLY, indacaterol/glycopyrronium II $0 \mu \mathrm{g} / 50 \mu \mathrm{g}$ once daily; $\mathrm{n}$, number of patients; SFC, salmeterol/fluticasone $50 \mu \mathrm{g} / 500 \mu \mathrm{g}$ twice daily.

(44.1\%-53.2\%). The incidence of pneumonia was lower with IND/GLY (IND/GLY, 3 patients; SFC, 14 patients). In a post hoc analysis, the difference in the incidence of pneumonia was found to be statistically significant $(P=0.0074)$. COPD (worsening) was the most commonly reported AE (GOLD B: IND/GLY, 19.5\%; SFC, 23\%, and GOLD D: IND/GLY, $17.9 \%$; SFC, 27.6\%). Maximum number of discontinuations due to AE was observed with SFC in the GOLD D subgroup (Table 3).

\section{Discussion}

The purpose of this post hoc ILLUMINATE/LANTERN pooled analysis was to explore the efficacy and safety of IND/GLY versus SFC in COPD patients in the GOLD B and GOLD D subgroups. The results showed a significant improvement in lung function with IND/GLY versus SFC in symptomatic COPD patients, irrespective of disease severity.
The current GOLD strategy provides a multimodal patient assessment model including airflow limitation, exacerbation history, and symptom severity, as a single measure may not fully reflect the disease severity. ${ }^{1}$ In both the GOLD B and GOLD D subgroups, dual bronchodilation with IND/ GLY demonstrated superior improvement in trough $\mathrm{FEV}_{1}$, weighted mean $\mathrm{FEV}_{1}$ from 0 to 12 hours and peak $\mathrm{FEV}_{1}$ versus SFC. These findings are consistent with previously reported trials, where IND/GLY showed a significant improvement in lung function versus SFC. ${ }^{6,7}$ Treatment differences in all the lung function parameters between IND/GLY and SFC were clinically significant in the overall pooled population and also in patients belonging to the GOLD B and GOLD D subgroups, except pre-dose trough $\mathrm{FEV}_{1}$ in the GOLD D subgroup (treatment difference, $80 \mathrm{~mL}$ ). Results of this analysis are supported by the outcome of the trials with other LABA/LAMAs, where the combination showed a significant improvement in lung

Table 2 Comparison of secondary efficacy outcomes at week 26

\begin{tabular}{|c|c|c|c|}
\hline \multirow[t]{2}{*}{ Parameters } & \multicolumn{3}{|c|}{ Least squares mean (95\% CI) treatment difference (IND/GLY versus SFC) } \\
\hline & Overall $(n=1,263)$ & GOLD B (n=809) & GOLD D (n=454) \\
\hline Peak FEV, $\mathrm{L}$ & $0.14^{* * *}(0.11,0.16)$ & $0.15^{* * *}(0.11,0.18)$ & $0.1 \mathrm{I} * * *(0.07,0.15)$ \\
\hline Peak FVC, L & $0.20 * * *(0.15,0.25)$ & $0.17 * * *(0.11,0.23)$ & $0.23 * * *(0.14,0.31)$ \\
\hline Pre-dose trough FVC, L & $0.19 * * *(0.15,0.24)$ & $0.18 * * *(0.12,0.23)$ & $0.22 * * *(0.13,0.30)$ \\
\hline TDI total score & $0.47^{\#}(0.16,0.79)$ & $0.59 *(0.19,1.00)$ & $0.35(-0.15,0.84)$ \\
\hline SGRQ total score & $-0.92(-2.33,0.48)$ & $-0.93(-2.68,0.82)$ & $-1.29(-3.61,1.02)$ \\
\hline Rescue medication use, puffs/day & $-0.20^{\#}(-0.40,-0.01)$ & $-0.14(-0.37,0.09)$ & $-0.36^{\#}(-0.70,-0.03)$ \\
\hline
\end{tabular}

Notes: $* * * P<0.0001, * P<0.005, * P<0.05$.

Abbreviations: $\mathrm{Cl}$, confidence interval; FEV , forced expiratory volume in I second; FVC, forced vital capacity; GOLD, Global Initiative for Chronic Obstructive Lung Disease; IND/GLY, indacaterol/glycopyrronium I I $0 \mu \mathrm{g} / 50 \mu \mathrm{g}$ once daily; SFC, salmeterol/fluticasone $50 \mu g / 500 \mu \mathrm{g}$ twice daily; SGRQ, St George's Respiratory Questionnaire; TDI, Transition Dyspnea Index. 


\section{IND/GLY $\quad$ SFC}

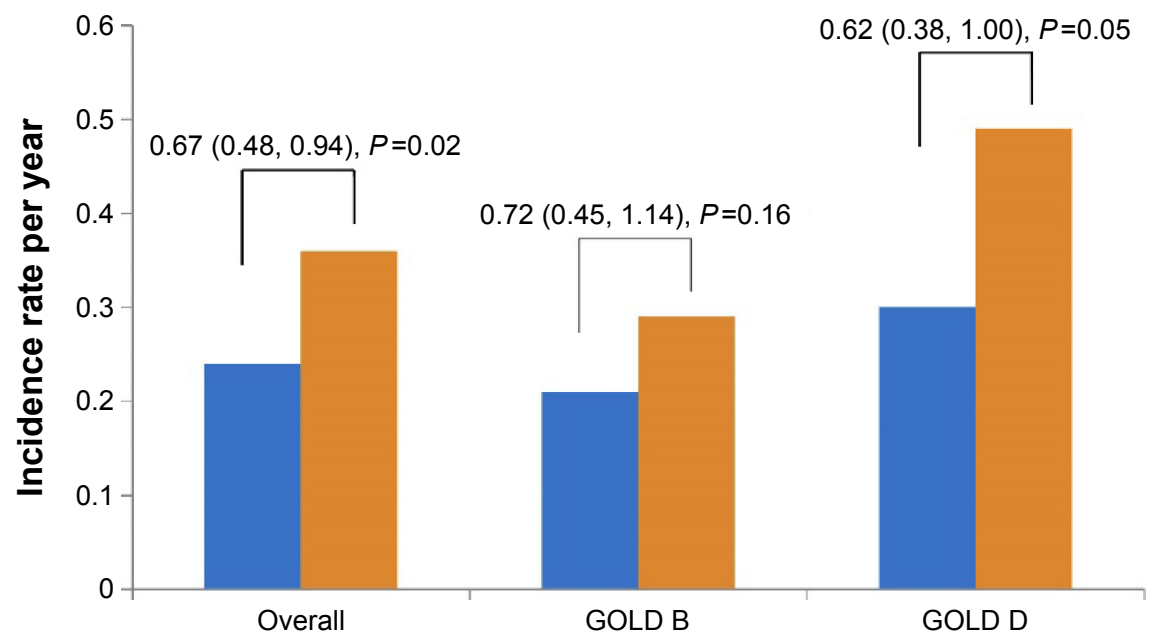

Figure 3 Annualized rate of moderate/severe exacerbations during the 26-week treatment period.

Abbreviations: GOLD, Global Initiative for Chronic Obstructive Lung Disease; IND/GLY, indacaterol/glycopyrronium I I0 $\mu \mathrm{g} / 50 \mu \mathrm{g}$ once daily; SFC, salmeterol/fluticasone $50 \mu \mathrm{g} / 500 \mu \mathrm{g}$ twice daily.

function versus SFC, irrespective of different severities of lung function impairment. ${ }^{8,9}$ In addition to $\mathrm{FEV}_{1}$, there was a significant improvement in FVC with IND/GLY versus SFC, which suggests that dual bronchodilation has additional benefits in reducing lung hyperinflation.
Improvement in symptoms is a major goal for the management of patients with COPD. Although the individual studies were not powered for detecting a difference in symptoms, a significant improvement in TDI total score and a significant reduction in the use of rescue medication

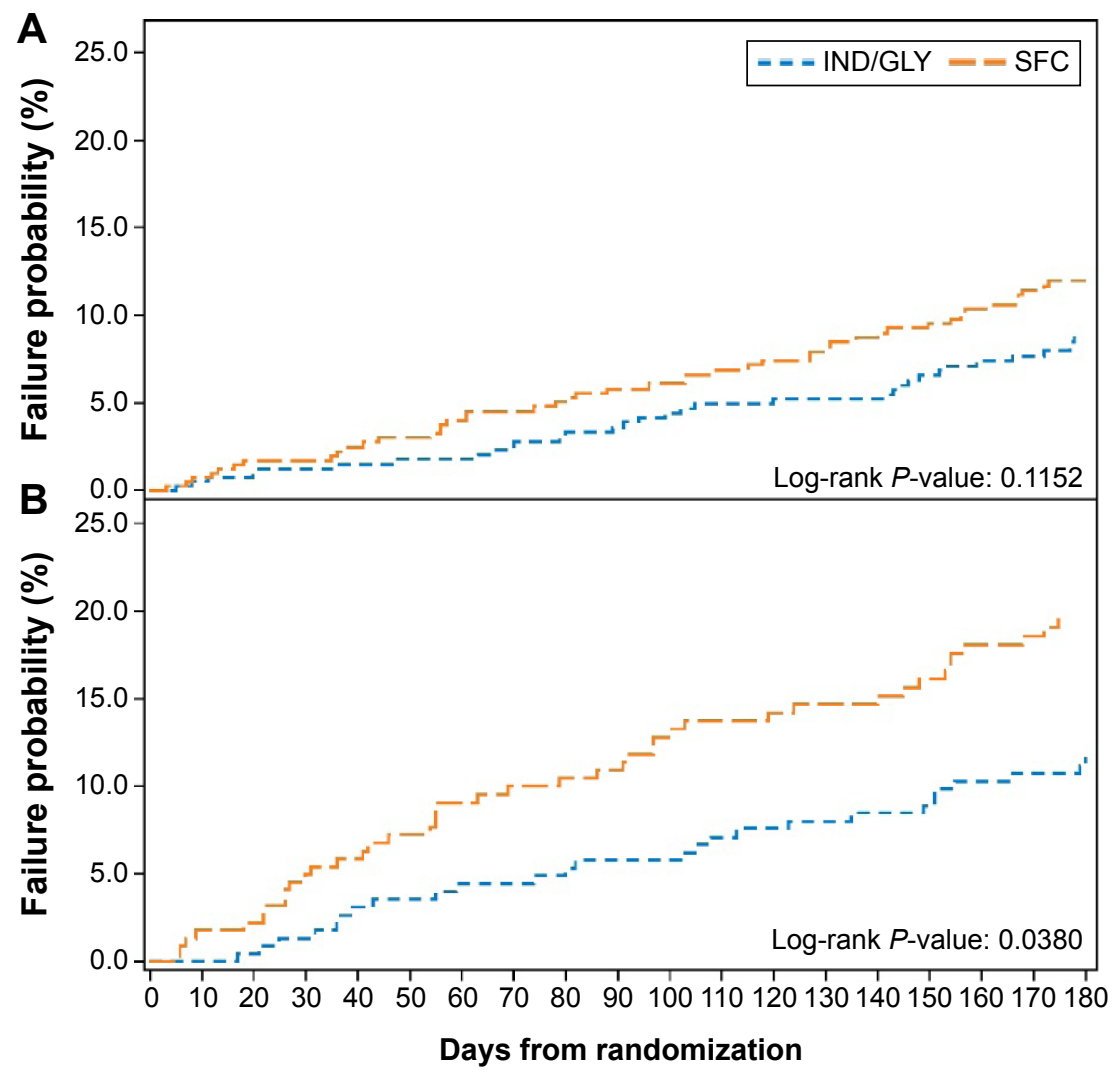

Figure 4 Time to first moderate/severe exacerbation during the 26-week treatment period: (A) patients in the GOLD B subgroup and (B) patients in the GOLD D subgroup. Abbreviations: GOLD, Global Initiative for Chronic Obstructive Lung Disease; IND/GLY, indacaterol/glycopyrronium I I0 $\mu \mathrm{g} / 50 \mu \mathrm{g}$ once daily; SFC, salmeterol/fluticasone $50 \mu g / 500 \mu g$ twice daily. 
Table 3 AEs, serious AEs, and deaths (safety set)

\begin{tabular}{|c|c|c|c|c|c|c|}
\hline \multirow[t]{2}{*}{ Parameters } & \multicolumn{2}{|l|}{ Overall } & \multicolumn{2}{|l|}{ GOLD B } & \multicolumn{2}{|l|}{ GOLD D } \\
\hline & $\begin{array}{l}\text { IND/GLY } \\
(n=630)\end{array}$ & $\begin{array}{l}\text { SFC } \\
(n=633)\end{array}$ & $\begin{array}{l}\text { IND/GLY } \\
(n=40 I)\end{array}$ & $\begin{array}{l}\text { SFC } \\
(n=408)\end{array}$ & $\begin{array}{l}\text { IND/GLY } \\
(n=229)\end{array}$ & $\begin{array}{l}\text { SFC } \\
(n=225)\end{array}$ \\
\hline Any $A E$ & $292(46.3)$ & $334(52.8)$ & 191 (47.6) & $217(53.2)$ & I0I (44.I) & $117(52.0)$ \\
\hline \multicolumn{7}{|l|}{ Any $A E s$ in $\geq 1.5 \%$ of any group } \\
\hline COPD worsening & $119(18.9)$ & $159(25.1)$ & $78(19.5)$ & $94(23.0)$ & $41(17.9)$ & $62(27.6)$ \\
\hline Nasopharyngitis & $67(10.6)$ & $74(11.7)$ & $38(9.5)$ & $45(11.0)$ & $29(12.7)$ & $29(12.9)$ \\
\hline Upper respiratory tract infection & $16(2.5)$ & $29(4.6)$ & $9(2.2)$ & $13(3.2)$ & $7(3.1)$ & $16(7.1)$ \\
\hline Headache & $12(1.9)$ & $13(2.1)$ & $8(2.0)$ & II (2.7) & $4(1.7)$ & $2(0.9)$ \\
\hline Hypertension & $9(1.4)$ & $9(1.4)$ & $8(2.0)$ & $5(1.2)$ & $\mathrm{I}(0.4)$ & $4(1.8)$ \\
\hline Oropharyngeal pain & $7(1.1)$ & $10(1.6)$ & $6(1.5)$ & $9(2.2)$ & I $(0.4)$ & I $(0.4)$ \\
\hline Upper respiratory tract infection bacterial & $12(1.9)$ & $6(0.9)$ & $8(2.0)$ & $3(0.7)$ & $4(1.7)$ & $3(1.3)$ \\
\hline Pneumonia & $3(0.5)$ & $14(2.2)$ & $2(0.5)$ & $7(1.7)$ & $\mathrm{I}(0.4)$ & $7(3.1)$ \\
\hline Bronchitis & $7(\mathrm{I} . \mathrm{l})$ & $7(I . I)$ & $3(0.7)$ & $5(1.2)$ & $4(1.7)$ & $2(0.9)$ \\
\hline Dyspnea & $7(1.1)$ & $10(1.6)$ & $3(0.7)$ & $3(0.7)$ & $4(1.7)$ & $7(3.1)$ \\
\hline AEs leading to discontinuation & $34(5.4)$ & $44(7.0)$ & $21(5.2)$ & $25(6.1)$ & $13(5.7)$ & $19(8.4)$ \\
\hline Any SAE & $33(5.2)$ & $49(7.7)$ & $22(5.5)$ & $29(7.1)$ & II (4.8) & $20(8.9)$ \\
\hline COPD & $7(1.1)$ & $20(3.2)$ & $3(0.7)$ & $9(2.2)$ & $4(1.7)$ & II (4.9) \\
\hline SAEs leading to discontinuation & $14(2.2)$ & $20(3.2)$ & $8(2.0)$ & $13(3.2)$ & $6(2.6)$ & $7(3.1)$ \\
\hline Deaths & $2(0.3)$ & I (0.2) & $2(0.5)$ & I (0.2) & $0(0.0)$ & $0(0.0)$ \\
\hline
\end{tabular}

Note: Values are presented as $\mathrm{n}(\%)$.

Abbreviations: AE, adverse event; GOLD, Global Initiative for Chronic Obstructive Lung Disease; IND/GLY, indacaterol/glycopyrronium II $0 \mu g / 50 \mu g$ OD; OD, once daily; $\mathrm{SAE}$, serious $\mathrm{AE}$; SFC, salmeterol/fluticasone $(50 \mu \mathrm{g} / 500 \mu \mathrm{g}$ twice daily).

were observed with IND/GLY versus SFC in the overall pooled population. However, the improvement in TDI total score with IND/GLY versus SFC failed to achieve clinical significance. This might be due to higher improvement in TDI total score with both active treatments (IND/ GLY, 2.57 and SFC, 2.10). As MCID is generally used for comparisons versus placebo, achieving a TDI total score of 2.57 units could be considered as clinically significant. Moreover, improvement in dyspnea and reduction in rescue medication use may be an indicator of additional benefit of IND/GLY over SFC in managing symptomatic patients with COPD.

Despite a significant improvement in lung function with IND/GLY versus SFC, the treatment differences in terms of SGRQ total score between IND/GLY and SFC were not found to be significant. This was not unexpected, since a similar finding was observed in the LANTERN, ILLUMINATE, ${ }^{6}$ and UMEC/VI (umeclidinium/vilanterol) versus $\mathrm{SFC}^{8}$ studies. Moreover, neither studies included in the analysis was powered to show the treatment differences in terms of patient-reported outcomes. However, the recently reported FLAME study showed a significant improvement in the SGRQ total score with IND/GLY versus SFC in COPD patients at risk of exacerbations. ${ }^{10}$ The discrepancy in these results may be due to the fact that the FLAME study was conducted in a population with more severe COPD and with a higher rate of exacerbations, and SGRQ total score has been associated with the risk of exacerbations. ${ }^{11}$
Although this study was conducted in a population that was largely not at high risk for exacerbation, IND/GLY showed a reduction in the number of exacerbations within the overall pooled population as well as in patients belonging to subgroups GOLD B and GOLD D. In the LANTERN study, the reduction in the rate and risk of moderate or severe exacerbations was significant with IND/GLY versus SFC in COPD patients with $\leq 1$ exacerbation in the previous year, whereas, in a post hoc analysis of the ILLUMINATE study, IND/GLY and SFC showed comparable results in patients without exacerbations in the previous year. ${ }^{12}$ Although the rates of exacerbation were low in this analysis, our findings are further supported by the results of the FLAME study that showed superior efficacy of IND/GLY versus SFC in terms of decreasing the risk of exacerbation (primary objective) and improving the lung function and quality of life over 52 weeks of treatment in COPD patients with a risk of exacerbation. ${ }^{10}$

The current GOLD strategy recommends LABA or LAMA monotherapy for patients in the GOLD B subgroup and LABA/ICS combination and/or LAMA for patients in the GOLD D subgroup as the first choice of treatment, while LABA/LAMA combination therapy is placed as an alternative therapy for both the classes. ${ }^{1}$ However, our findings suggest the need to reexamine current recommendations for COPD patients in the GOLD B and GOLD D subgroups. In this pooled analysis, IND/GLY showed a significant improvement in lung function and also reduction in exacerbations 
versus SFC in patients belonging to GOLD B and GOLD D subgroups. Previously, the SPARK study showed the benefit of LABA/LAMA combination versus LAMA monotherapy in terms of reducing exacerbations in severe-to-very severe COPD patients at risk of exacerbation. ${ }^{13}$ The FLAME study showed $14 \%$ (rate ratio [RR], 0.86; 95\% confidence interval $[\mathrm{CI}]: 0.69,1.06 ; P=0.154)$ and $17 \%(\mathrm{RR}, 0.83 ; 95 \%$ CI: $0.74,0.92 ; P<0.001)$ reduction in moderate or severe exacerbation with IND/GLY versus SFC in the GOLD B and GOLD D subgroups, respectively. ${ }^{10}$ Although there are data that support the role of LABA/ICS combination in reducing the risk of exacerbations, ${ }^{14}$ their uses are associated with AEs, such as pneumonia and hypothalamic-pituitary-adrenal axis suppression. ${ }^{15-17}$

In this analysis, the safety profile of IND/GLY was comparable with SFC in both the GOLD B and GOLD D subgroups with the exception of a higher incidence of pneumonia with SFC.

There are some limitations of this post hoc analysis. Patients categorized into GOLD B and GOLD D could not be precisely modeled according to the GOLD 2011 strategy, specifically for the ILLUMINATE study, as the study was planned before the strategy was available. Although both the ILLUMINATE and LANTERN studies compared IND/ GLY and SFC in terms of efficacy and safety, we need to acknowledge that there were few differences in patient characteristics and end points. No patient in the ILLUMINATE study experienced an exacerbation in the previous year; however, the LANTERN study included patients with and without a history of exacerbation in the previous year, and $20 \%$ of the enrolled subjects had an exacerbation in the previous year. Exacerbation was analyzed post database lock in the ILLUMINATE study, whereas in the LANTERN study it was a prespecified exploratory end point. Most of the patients $(90 \%)$ in this pooled analysis were having infrequent exacerbations. Thus, this analysis includes only a small number of patients who were in GOLD D based on exacerbations history.

\section{Conclusion}

In this LANTERN/ILLUMINATE pooled analysis, IND/ GLY demonstrated superior efficacy versus SFC in the overall population as well as in the GOLD B and GOLD D subgroups. The trend of improvement with IND/GLY versus SFC was similar in the GOLD B and GOLD D subgroups in all the parameters tested. Considering the superiority of IND/ GLY over SFC in this post hoc analysis and other published data, in patients in the GOLD B and GOLD D subgroups, it may be concluded that LABA/LAMA combination can be the first-line therapy in this patient group.

\section{Acknowledgments}

This study was sponsored by Novartis Pharma AG. The authors would like to thank patients and staff at the participating centers. The authors also thank Santanu Sannigrahi (professional medical writer, Novartis Healthcare Pvt. Ltd., Hyderabad, India) for assistance in the preparation of this manuscript. Writing support was funded by the study sponsor.

This study was published as an abstract and presented at the European Respiratory Society International Congress 2015.

\section{Author contributions}

Coordinated investigator centers for LANTERN and ILLUMINATE studies, respectively, collected clinical data, and contributed to the writing of the manuscript: NZ and CV. Centrally coordinated, educated, and monitored the centers: MH. Helped to design the studies, overlooked statistical analyses and helped to write the manuscript: $\mathrm{MH}$, KM, RF, GB, FP and DB. All the authors contributed extensively and approved the manuscript before submission. All authors also contributed toward data analysis, drafting and critically revising the paper and agree to be accountable for all aspects of the work.

\section{Disclosure}

This study was sponsored by Novartis Pharma AG. CV reports grant support and personal fees from Grifols, and personal fees from Almirall, AstraZeneca, Boehringer Ingelheim, Chiesi, Cytos, GlaxoSmithKline, Janssen, Mundipharma, Novartis, Takeda, and Cipla outside the submitted work. MH, $\mathrm{KM}, \mathrm{RF}, \mathrm{GB}, \mathrm{FP}$, and DB are the employees of the study sponsor, Novartis. The authors report no other conflicts of interest in this work.

\section{References}

1. Global Initiative for Chronic Obstructive Lung Disease (GOLD). Global Strategy for the Diagnosis, Management, and Prevention of Chronic Obstructive Pulmonary Disease. 2016. Available from: http://www. goldcopd.org/. Accessed March 14, 2016.

2. Barrecheguren M, Monteagudo M, Ferrer J, et al. Treatment patterns in COPD patients newly diagnosed in primary care. A population-based study. Respir Med. 2016;111:47-53.

3. Price D, West D, Brusselle G, et al. Management of COPD in the UK primary-care setting: an analysis of real-life prescribing patterns. Int $J$ Chron Obstruct Pulmon Dis. 2014;9:889-904.

4. Bateman ED, Ferguson GT, Barnes N, et al. Dual bronchodilation with QVA149 versus single bronchodilator therapy: the SHINE study. Eur Respir J. 2013;42(6):1484-1494.

5. Matera MG, Rogliani P, Cazzola M. QVA149 (indacaterol/glycopyrronium) for the treatment of chronic obstructive pulmonary disease. Expert Opin Pharmacother. 2015;16(7):1079-1090. 
6. Vogelmeier CF, Bateman ED, Pallante J, et al. Efficacy and safety of once-daily QVA149 compared with twice-daily salmeterol-fluticasone in patients with chronic obstructive pulmonary disease (ILLUMINATE): a randomised, double-blind, parallel group study. Lancet Respir Med. 2013;1(1):51-60.

7. Zhong N, Wang C, Zhou X, et al. LANTERN: a randomized study of QVA149 versus salmeterol/fluticasone combination in patients with COPD. Int J Chron Obstruct Pulmon Dis. 2015;10:1015-1026.

8. Donohue JF, Worsley S, Zhu CQ, Hardaker L, Church A. Improvements in lung function with umeclidinium/vilanterol versus fluticasone propionate/salmeterol in patients with moderate-to-severe COPD and infrequent exacerbations. Respir Med. 2015;109(7):870-881.

9. Beeh KM, Derom E, Echave-Sustaeta J, et al. The lung function profile of once-daily tiotropium and olodaterol via Respimat ${ }^{\circledR}$ is superior to that of twice-daily salmeterol and fluticasone propionate via Accuhaler $^{\circledR}$ (ENERGITO ${ }^{\circledR}$ study). Int J Chron Obstruct Pulmon Dis. 2016;11:193-205.

10. Wedzicha JA, Banerji D, Chapman KR, et al. Indacaterolglycopyrronium versus salmeterol-fluticasone for COPD. N Engl J Med. 2016;374(23):2222-2234.

11. Martin AL, Marvel J, Fahrbach K, Cadarette SM, Wilcox TK, Donohue JF. The association of lung function and St. George's respiratory questionnaire with exacerbations in COPD: a systematic literature review and regression analysis. Respir Res. 2016;17:40.
12. Banerji D, Fedele MJ, Chen H, Kim HJ. Dual bronchodilation with QVA149 reduces COPD exacerbations: results from the IGNITE program (OS36: COPD 3). Respirology. 2013;18:69-70.

13. Wedzicha JA, Decramer M, Ficker JH, et al. Analysis of chronic obstructive pulmonary disease exacerbations with the dual bronchodilator QVA149 compared with glycopyrronium and tiotropium (SPARK): a randomised, double-blind, parallel-group study. Lancet Respir Med. 2013;1(3):199-209.

14. Nannini LJ, Poole P, Milan SJ, Kesterton A. Combined corticosteroid and long-acting beta(2)-agonist in one inhaler versus inhaled corticosteroids alone for chronic obstructive pulmonary disease. Cochrane Database Syst Rev. 2013;8:CD006826.

15. DiSantostefano RL, Sampson T, Le HV, Hinds D, Davis KJ, Bakerly ND. Risk of pneumonia with inhaled corticosteroid versus long-acting bronchodilator regimens in chronic obstructive pulmonary disease: a new-user cohort study. PLoS One. 2014;9(5):e97149.

16. Lee MC, Lee $\mathrm{CH}$, Chien SC, et al. Inhaled corticosteroids increase the risk of pneumonia in patients with chronic obstructive pulmonary disease: a nationwide cohort study. Medicine (Baltimore). 2015;94(42):e1723.

17. Cavkaytar O, Vuralli D, Arik Yilmaz E, et al. Evidence of hypothalamicpituitary-adrenal axis suppression during moderate-to-high-dose inhaled corticosteroid use. Eur J Pediatr. 2015;174(11):1421-1431.
International Journal of COPD

\section{Publish your work in this journal}

The International Journal of COPD is an international, peer-reviewed journal of therapeutics and pharmacology focusing on concise rapid reporting of clinical studies and reviews in COPD. Special focus is given to the pathophysiological processes underlying the disease, intervention programs, patient focused education, and self management protocols.

\section{Dovepress}

This journal is indexed on PubMed Central, MedLine and CAS. The manuscript management system is completely online and includes a very quick and fair peer-review system, which is all easy to use. Visit http://www.dovepress.com/testimonials.php to read real quotes from published authors. 